\title{
CYBER-BULLYING VICTIMIZATION: HOPE FOR LIFE AMONG VICTIMIZED UNIVERSITY GRADUATES
}

\author{
Faiz Ul Hassan Shah ${ }^{1}$ and Irshad Hussain ${ }^{2 *}$
}

\begin{abstract}
This research study is focused on cyber-bullying victimisation, as well as the hope of the victimized graduates to live their lives fearlessly. For this purpose, university victimised graduates were interviewed using the snowball sampling technique. The results of the study are alarming in terms of their nature and intensity -the victimized graduates were blackmailed and thinking of suicide, they were socially stigmatized, they sacrificed their lives and some surrendered or compromised with what the bully said to do. They isolated themselves and alike. The study suggested that students should avoid sharing their personal information via social networking sites with those people who are not known to them. The study also suggested that parents should keep an eye on social media accounts as well as ICTs' devices of their children. Also, educational intuitions should organize awareness seminars to make students aware of cyber-bullying and how to escape from being victimized.
\end{abstract}

Keywords: Cyber-bullying; Social Networking Sites; Hope for Life; Bullying Victimization; Information and Communication Technology; University Victimized Graduates.

\section{INTRODUCTION}

Today, in the age of technological transformations and digital innovations, adolescents have become overindulgent in the use of technology and the internet. Due to the wide access to cyber technology, it has become a norm for youth to profligately spend their time on the internet and web surfing. It is even viewed as their avenue of freedom to connect to the social world and

\footnotetext{
${ }^{1}$ PhD Scholar, Department of Educational Training, The Islamia University of Bahawalpur, Bahawalpur, Pakistan. Email: faizulhassan.fs@gmail.com

${ }^{2}$ Professor, Department of Education, The Islamia University of Bahawalpur, Bahawalpur, Pakistan. Email: irshad.hussain@iub.edu.pk (iD https://orcid.org/0000-0001-7213-6474

*Corresponding Author
} 
has become a leisure activity of their choice. In this way, youngsters not only engage in networking, entertainment, and knowledge-seeking but also in certain negative activities (Griffiths \& Wood, 2000). Everything from information retrieval, surfing, to social activities and interactions are carried out on the internet. While the burgeoning use of the internet has helped to support and enhance conventional technologies, it has also opened the door to new ideas in a wide range of areas, including education (Sun \& Chen, 2016).

There are several reasons why students utilize communication technologies. Youngsters are heavily reliant on social networking sites to develop their social networks, and some of them are also reliant on them for academic reasons (Koranteng, Wiafe, \& Kuada, 2019). The depth and breadth of studies on web technologies exist in developed nations, but the same cannot be said for developing nations, which lack the same depth and vigour of research. Low living standards, rapidly increasing population, low per capita income, and a general economic and technical reliance on established economies have all been characteristics of developing nation prevailing circumstances for many years now (Tokareva, Smirnova \& Orchakova, 2019). Similarly, in the point of view of Abaido (2020), computers and mobile phones, as a result of recent technological advancements, have emerged as new venues for social contact among both children and adults. But there are additional platforms via which young people may participate in bullying behaviours, such as email, texting, and posting on social networking sites. A person who is unable to defend him or herself is targeted by this aggressive behaviour known as cyberbullying, internet aggression, or electronic aggression, which is defined as an aggressive act that is deliberately and repeatedly carried out in an electronic context against a person who is unable to defend him or herself (Abaido, 2020).

As a result of the increasing use of information and communication technology (ICT) as a mode of communication via phones, tablets, and laptops, a contemporary scenario has developed. A situation in which there is a "generation gap" between the younger and older generations. The use of technology, technological applications and the instillment of the internet in everyone's life is a new phenomenon to an older generation, thus bullying situations are frequently overlooked by parents who are ignorant of the risks of technology for children (Carnoy, 2004). Furthermore, new mobile phone applications are being developed at an increasing pace, which many adults may not be aware of due to their ineptness to the new technological interface. Consider the picture messaging application by Snapchat, which enables users to send messages or videos to each other text that are immediately erased once they have been seen by the 
recipient. But this is not always the case, and it is easy to preserve the image or video and use it afterwards to annoy the person who took the photo or video (Lindsay, 2011). In addition, students use social networking sites to fulfil their own needs, establish social relationships as required, quell their curiosity, and enjoy their liberty (Urista, Dong, \& Day, 2009).

Cyberbullying is a type of internet bullying that occurs on the internet. People utilize the internet for essential issues in life, but as with everything that has benefits and downsides, there are inevitably many drawbacks of excessive internet usage (Cuervo, Martínez, Quintana, \& Amezaga, 2014). Many students suffer from cyberbullying through social networking sites like Facebook, WhatsApp, Skype, Twitter, Snapchat, Instagram, and LinkedIn. It is a new type of bullying (Dutta, De, \& Chandan, 2017). Although cyberbullying is a relatively new practice, the harmful effects of such conduct have been reported by various sources (Nixon, 2014). There has been a lot of discussion in the media about how cyberbullying differs from traditional forms of harassment. There is a link between being a victim of traditional bullying and cyberbullying, and many digital victims report both traditional and cyberbullying. In other words, it is a cyberharassment (Slonje, Smith, \& Frisén, 2013). According to Zalaquett \& Chatters, (2014), students who are bullied online in school become victims of cyberbullying at the college level (Zalaquett \& Chatters, 2014). In the opinion of Faucher, Jackson \& Cassidy, (2014), the incidence of cyberbullying among university graduates is increasing day by day. The viewpoint of relational aggression characterizes the bullying behaviour of girls as more concealed and secret than the bullying of boys (Faucher, Jackson \& Cassidy, 2014). Research has shown that most girls who use social networking sites keep their relationships secret. Consequently, when they become victims of cyberbullying, they cannot tell others (Abaido, 2020).

Anxiety, depression, drug abuse, stress, and sleep deprivation have all been linked to cyberbullying and have also induced a number of other severe mental health consequences (Goebert, Else, Matsu, Chung-Do \& Chang, 2011). In addition, one study found adolescent cyber-victims had suffered at least one stress-related symptom as a consequence of their cybervictimization (Castile, 2013).

Researchers from around the world are working on this concern, to know the various aspects related to cyber-bullying behaviour including the perspective of cyber-victims to those of cyber-bullies. According to most surveys, teenage students who are most likely to be victims of cyberbullying are mentally and emotionally affected (Donegan, 2012). The mental health consequences of cyber victimization have also been shown to be similar to those of 
conventional victimization. Cyber victimization has an impact on teenage health that goes beyond traditional victimization. Cyberbullying can lead to unsteadiness (Espelage, \& Holt, 2001; Reid, Holt, Bowman, Espelage, \& Green, 2016). On the other hand, researchers' apprehension is concentrated on the psychological effects that internet users experience. The psychological, social, and physical health of both bullies and victims engaged in cyberbullying is thought to be negatively impacted as a result of the behaviour. Cyberbullying may cause mental health issues in a similar way to conventional bullying, which includes verbal, relational, and physical bullying (Schenk \& Fremouw, 2012). According to Zalaquett \& Chatters, (2014), cyberbullying has an enormous impact on the psychological and mental wellbeing of college students. Relatedly, this study also indicates that $20 \%$ of the college students who were sampled for the study data were victims of cyberbullying, and $50 \%$ of those students were victims of cyberbullying in high school.

\section{LITERATURE REVIEW}

Cyber-victimized students have greater depressive symptoms and academic difficulties than non-victimized students and cyberbullies (Okumu, Kim, Sanders, Makubuya, Small, \& Hong, 2020). As a consequence of cyberbullying, people's trust is first diluted. When victims seek assistance, they are often dismissed as untrustworthy. Being believed is the first step in the restoration of trust. When victims seek help and are believed, they begin to realize that they are suffering from a loss of trust and that, with hard effort, they can recover. As a result, they learn to trust others as their sense of trust is re-established. This newfound trust is no longer a blind trust, but rather an informed trust that helps in the process of mending the wounds that have been created (Camp, 2016).

\section{Perception about Cyber-bullying}

"Intentional and repetitive abuse committed via computers, mobile phones, and other electronic devices" is defined as cyber-bullying. At the extreme end, cyber-bullying is simple to spot: repeated threats, many embarrassing postings, and numerous abusive messages are common signs. But what about that somewhat indecent internet joke aimed at no one in particular (Patchin \& Hinduja, 2015). If a student makes a single cruel remark about a classmate on a publicly accessible page, it is considered cyber-bullying, if the first student was aware that the post would be seen by others (Patchin, \& Hinduja, 2006). However, the introduction of smartphones in recent years has made it easy to send and receive emails as well as to use these phones to access the internet in general (Slonje, Smith, \& Frisén, 2013). Similarly, through the 
internet, mobile phones, computers, tablets, and other cyber gadgets made two-way communication extremely simple. While the advantages are substantial, the potential for abuse is equally obvious. People who use these gadgets to converse with others may inadvertently hurt others. It may be cyber-bullying or cyber-harassment (Li, Wang, \& Pustaka, 2015).

\section{Realization of Being a Victim of Cyber-bullying}

According to Hazlyna (2021), recently, a high number of students were found to be victims of cyberbullying. This represents the total number of times they have been victimised at the institution, whether by another student, a stranger, or a faculty member. When asked openly whether they had been cyber-bullied by a friend or acquaintance at the university in the previous 12 months, more female than male students answered yes, while when asked if they had been cyber-bullied by someone they did not know, more male than female students said yes. Only $2 \%$ of students in both groups reported a faculty member had cyberbullied them (Faucher, Jackson, \& Cassidy, 2014).

\section{Victims Experiences of Cyber-bullying}

In this perspective, Crosslin \& Golman (2014) assert that "Cyber-bullying" experiences fluctuate greatly depending on the context and individual variables, solutions need a deeper knowledge of the phenomena in individuals or groups. Cyberbullying is common among young people all over the world, but hardly any study was conducted on university students and working adults. While according to the point of view of Faucher, Jackson, and Cassidy (2014), victims subjected to cyberbullying suffered from negative emotions such as shame, loneliness, helplessness, fear, and negative emotions. Thus, cyberbullying victims demonstrate more anxiety, paranoia, depression, fading pro-social behaviour (Bork-Hüffer, Mahlknecht, \& Kaufmann, 2021).

\section{Effects of Cyber-bullying on Victims}

According to recent research, being cyber-bullied may lead to severe physical, social, and psychological issues, such as depressive symptoms and stress. It has also been observed that students with depressive symptoms suffer greater emotional stress as a result of cyber-bullying than children with less or no depressive symptoms (Dehue, Bolman, \& Vollink, 2008).

\section{Ability to Cope with Difficult Circumstances Constructively}

The respondents of this study were victims of cyberbullying aged 17 or above, thus a certain degree of maturation and problem-solving ability was anticipated in comparison to the younger participants. This result is consistent with research that has focused on both young adults and 
children (Schenk, \& Fremouw, 2012). On the other hand, personal interactions, emotional intelligence, and social support may have played a role in the older students' decision not to act on suicidal thoughts or intentions (Hinduja, \& Patchin, 2010).

\section{Immediate Sense after Cyber-bullying Victimization}

Suicidal ideation is a troubling statistic, with 71/216 (39.9\%) having had the issue at least once in their lifetime (Kelly, Newton, Stapinski, Slade, Barrett, Conrod, \& Teesson, 2015). Victims exhibited higher suicidal behaviours, not just in terms of frequency of suicidal thoughts, but also in terms of planning. It is worth noting that the present research only gives estimates for suicide intentions; it is unclear if the victims followed through on their plans (Hinduja \& Patchin, 2010). There were significant differences between males and females related to emotional reactions among the bullies, females experiencing more emotions such as depression, regret, and pity for the victim than males (Hazlyna, 2021; Campbell, Spears, Slee, Butler, \& Kift, 2012).

\section{Factors contributing to the Sense of Hope for Life}

The basic concept of social responsibility is that humans have an obligation to make peace in the world and among human relations. This may be accomplished by encouraging free human beings to pursue their goals as long as they do not hurt others (Cohen-Almagor, 2017). All concerned stakeholders, including parents, school instructors and administrators, civil society groups and businesses, nations, and the international community at large, should share responsibility and accountability. Bullying has an impact on everyone (Craig et al., 2020).

Bullying in all forms, including cyber-bullying, is a major worry for both children and parents (Capital FM, 2017). Children and teenagers must learn to deal with cyber-bullying. Concerned NGOs must engage with individuals who have been recognised as bullies, addressing their bad conduct, and attempting to alter attitudes (Cohen-Almagor, 2020; 2017).

\section{Stumbling Blocks on the Path of Hope for Life}

Wilhelms and Reyna (2013) argue that youngsters are sensitive and thoughtless; that they do not try to weigh the implications of anything, and that these thoughts do not prepare them for the ongoing and immediate challenges they will face as a result of being a victim. Because of their emotional and libertarian behaviour, teenagers cannot assume this. According to Nelson (2011), children have strong emotions, but they lack the ability to control their thoughts because their prefrontal cortex has not developed adequately. 


\section{Steps toward Rehabilitation}

In the point of view of Cohen-Almagor, (2017), there is a need to create programmes that address the issue. These programmes should raise awareness of the difference between teenagers' emotional and mental development, their risk-taking tendency, and strategies to deal with peer pressure. To fight bullying behaviour, both offline and online, a collaboration between parents, schools, governments, non-governmental organisations, and Internet corporations is required. Freedom should be accompanied by accountability. Bullying and cyber-bullying will become less prevalent if all parties conduct themselves appropriately, and many human lives will be spared. Relevant stakeholders must accept responsibility for their activities in order to provide the groundwork for change and development in their life chances and prospects (Cohen-Almagor, 2020; 2017).

\section{Mental and Psychological Well-Being}

According to Kowalski and Limber (2013), in gender-based perspectives, males were reported to have more negative psychological disorders such as anxiety and sadness, as well as physical health issues like headaches and sleep impairments, than females, both as victims and bullies.

\section{Excessive uses of Social Networking Sites through ICT Gadgets}

In the views of Urista, Dong, \& Day (2009) social networking sites have an easy and simple way to communicate with family, friends, and others. Individual users' needs and desires may also be met on a continuous and immediate basis. To meet these needs and desires in the past, individuals utilised a variety of face-to-face human contact and mainstream media such as television, radio, and cinema. Due to issues such as inaccessibility, unresponsiveness, programming, and scheduling, these gratifications were often postponed. on the other hand, social networking sites vary from other kinds of mass media in that they allow people to actively participate in sending messages to others in their social network (Urista, Dong, \& Day, 2009).

\section{Coping with the Consequences of Cyber-Bullying}

Different ways for coping with cyber-bully victims described by students include concealing one's identity, informing someone, ignoring the event, deleting the communications, and, curiously, harassing the bully (Dehue et al., 2008). In contrast, 13.2 percent of 54 college students in an American focus group research dealt with cyber-bullying on their own, claiming independence and autonomy as reasons for not reporting cyberbullying to others when it occurred (Crosslin \& Golman, 2014). Similarly, the prevalence of bullying and being bullied; 
efforts by parents to stop bullying behaviour; and communication on bullying and being bullied (Dehue et al., 2008) need to be addressed properly.

There has been relatively little research on cyber-bullying and hope for life among the victimized university graduates. On the one hand, this is an entirely novel concept. The number of individuals pursuing higher education is growing on a daily basis. Whereas cyberbullying has become more prevalent. Some students get engaged in undesirable activities as a result of the open atmosphere that exists in universities. As a result, relatively little research has been conducted in this field in Pakistan. Thus, there remains a significant gap in this area. Relatively, this research aimed to identify the factors promoting hope for the life of victims of cyberbullying at the university level.

\section{RESEARCH QUESTIONS}

1. Are university graduates aware of cyber-bullying?

2. What are the effects of cyber-bullying on victimized university graduates?

3. What are the factors which contribute towards hope for life among victimized university graduates?

4. How can university graduates avoid becoming the victim of cyber-bullying?

\section{METHODOLOGY}

The present study was of descriptive nature, and it used a survey approach for data collection. The study used "Action Research Study Design" of qualitative research. Such study design focuses on examining the current situation or status of a phenomenon or a practice; and generally, tries to improve the situation by seeking feasible actions or strategies (Speziale, Streubert, \& Carpenter, 2011). Whereas, qualitative research explores the nature of a phenomenon, its context and perspective of being perceived (Busetto, Wick, \& Gumbinger, 2020); and the data of which generally comes in the form of words (Punch, 2013).

\section{The Context}

As cyber-bullying victimized university graduates were subjects of the study, therefore, the context of the study consisted of academic as well as social situation(s). The context was academic as the victims had been studying in an institution of Higher Education in Pakistan i.e. The Islamia University of Bahawalpur, Pakistan; and it was social as the graduates became victims in the environment of the university and after getting through the university they were 
living in the society. The study addressed cyber-bullying victimization -an issue of social significance at the Islamia University of Bahawalpur, Pakistan.

\section{Participants of the Study}

Cyber-bullying -the phenomenon under investigation is an overly sensitive topic and of a socially stigmatizing nature in Pakistan. It was difficult for the researchers to identify the cyberbullying victims and elicit their opinions. Therefore, the snowball sampling technique was used to approach the specific respondents for data collection. This technique is most useful for the collection of data from the victims of cyberbullying.

The participants of the study consisted of the cyber-bullying victimized university graduates of the Islamia University of Bahawalpur, Pakistan. A total of twelve cyber-bullying victimized university graduates were identified and approached for permission to participate in the study. The participation in the survey was on a volunteer basis. Despite rapport building and confidence gaining, assurance of confidentiality of their identity and provided information; only eight victimized graduates agreed to participate in the survey.

Table 1. Gender Basis Frequency of Victims

\begin{tabular}{lll}
\hline Gender & Frequency & $\%$ \\
\hline Male & 2 & 25.0 \\
Female & 6 & 75.0 \\
Total & 8 & 100.0 \\
\hline Source: Study Analysis
\end{tabular}

Table 1 demonstrates that in the study sample, $25 \%$ of victims were male, and $75 \%$ were female. So, the majority of the victims were female in this regard.

Table 2. Victims' Frequency based on Age

\begin{tabular}{ccc}
\hline Age & Frequency & \% \\
\hline 26 & 1 & 12.5 \\
27 & 1 & 12.5 \\
28 & 1 & 12.5 \\
29 & 2 & 25.0 \\
30 & 2 & 25.0 \\
32 & 1 & 12.5 \\
Total & 8 & 100.0 \\
\hline
\end{tabular}

Source: Study Analysis

Table 2 illustrates that $12.5 \%$ of victims were 26 years old, $12.5 \%$ victims were 27 years old, $12.5 \%$ of victims were 28 years old, $25 \%$ of victims were 29 years old, $25 \%$ of victims were 
30 years old and 12.5 were 32 years old. So, the majority of the victims was under 30 years of age.

Table 3. Educational Qualification of Victims

\begin{tabular}{ccl}
\hline Residence & Frequency & \% \\
\hline BS/MA/M.Sc. & 6 & 75.0 \\
MS/M.Phil. & 2 & 25.0 \\
Total & 8 & 100.0 \\
\hline
\end{tabular}

Source: Study Analysis

Table 3 revealed that $75 \%$ of victims had BS/MA/M.Sc. qualification, while $25 \%$ had MS/M.Phil. qualification. So, most of the students were BS/MA/M.Sc. qualified.

Table 4. Job Status of Victims

\begin{tabular}{ccl}
\hline Job Status & Frequency & \% \\
\hline Govt. & 3 & 37.5 \\
Private & 1 & 12.5 \\
Homemaker & 4 & 50.0 \\
Total & 8 & 100.0 \\
\hline
\end{tabular}

Source: Study Analysis

Table 4 reveals that $37.5 \%$ of victims had a government job, $12.5 \%$ of victims were employed in private firms, and $50 \%$ of female respondents were homemakers. So, the majority of victims were married females.

Table 5. Victims' Frequency on the Location

\begin{tabular}{lcc}
\hline Residence Location & Frequency & $\%$ \\
\hline Urban & 2 & 25.0 \\
Rural & 6 & 75.0 \\
Total & 8 & 100.0 \\
\hline
\end{tabular}

Source: Study Analysis

Table 5 presented that, around $25 \%$ of respondent victims were from urban areas, and $75 \% \%$ were from rural areas. So, most of the victims were from the rural locality. Overall, the sample was $75 \%$ female and $25 \%$ male; $87.5 \%$ of victims were under 30 years of age and rest $12.5 \%$ were over 30 years of age; 75\% of the respondents' were BS / M.A / MS.C and the remaining $25 \%$ were M.Phil. qualified; $75 \%$ respondents were from rural areas and the others $25 \%$ belonged to urban areas; $37.5 \%$ of the respondents' had government jobs, $12.5 \%$ had private 
jobs and the remaining $50 \%$ were female and they were not doing any job but were stay at home homemakers.

\section{Instrument of the Study}

In the light of the literature review, the researchers prepared an interview protocol that consisted of different aspects of cyber-bullying victimization. These were awareness about cyber-bullying, experiencing cyber-bullying, effects of cyber-bullying, immediate feeling after becoming victimized, coping with circumstances after becoming victimized, factors leading towards hope for life, facing obstacles in the way towards hope for life, recovery and how to avoid cyber-bullying.

The interview protocol was validated through expert opinion. The interview protocol consisted of twelve questions besides the demographic information of the respondents. The demographic information included gender, age, education level, employment, and location (urban or rural). The interview items were flexible and translated into Urdu version in order to make it simpler for the interviewee. It enabled the respondents to easily respond to the questions. Generally, the victims were asked about their cyber-bullying, its effects, and their aspirations behind their decision for their rehabilitation towards normal life activities.

\section{Data Collection Procedure}

Keeping in view the nature of the study i.e., the sensitivity of the issue and social stigmatization; the snowball sampling technique was used. The researchers personally contacted the respondents to gather the data. Firstly, the researchers built rapport with the cyber-bullying victimized graduates and won their confidence which is considered necessary for such social research studies; secondly, the respondents were assured about the confidentiality of their identity and the provided information; thirdly, interviews were conducted at their convenience; and fourthly, a respectful, pleasant, and encouraging \& appreciating environment was maintained during the entire course of the interview. Total eight interviews were conducted individually, and audio recorded with the permission and/ or consent of the respondents. Notes of some important points, pattern of voice (sad, sighs, fear etc.) gestures and body language were taken. The researchers transcribed the audio recorded interviews in Urdu Language and translated them into English for a thorough thematic analysis of the data. 


\section{DATA ANALYSIS}

This study used a qualitative thematic analysis method. It is "an appropriate method of analysis for seeking to understand experiences, thoughts, or behaviours across a data set" (Kiger \& Varpio, 2020, p. 1). According to Sundler, Lindberg, Nilsson and Palmér (2019), this method is used to get an understanding of the patterns of meaning from data on life experiences which may be obtained by using thematic analysis. Typically, the analysis starts with textual data for interpreting and organizing its meaning and transforming these meanings into patterns and then themes (Sundler, Lindberg, Nilsson, \& Palmér, 2019). Hence, the themes were constructed or derived from data. The six-step thematic analysis process (Kiger \& Varpio, 2020) was adopted. These steps were familiarizing with data, generating initial codes, searching for themes, reviewing themes, defining, and naming themes, and producing the report.

\section{RESULTS}

According to the findings of the qualitative thematic analysis of the collected data the answers to the interviews, are presented and discussed below:

\section{Becoming Aware of Cyber-Bullying}

The perception of cyber-bullying varies from person to person. When the respondents were asked about their perception of cyber-bullying, the majority of the respondents said that they were not aware of the term "cyber-bullying" before. One of the respondents said that she learned about the term when she discussed her situation with her colleague that she had faced through a Facebook friend. Another participant responded that she had been exploited because of her trust as she had given her mobile phone to someone in the family for repair, and he had taken away her photographs and blackmailed her by tempering/ photoshop these photographs. Another respondent revealed that she had been harassed since she had handed her laptop over to someone for repair and he copied her photos from it. One of them said that she came to know about cyber-bullying when she faced the problem. According to one of the respondents, cyberbullying is, "Horrifying someone by using a mobile phone or any other electronic device while connected to the internet." A respondent sadly affirmed cyber-bullying as an act of tormenting someone via the use of a mobile phone or other devices while connected to the internet.

One of the respondents revealed that she became aware of her situation as her suffering and abuse started to escalate. When a close friend of hers requested to send some photos of her, she gladly consented. She emailed those photos and requested for them to be deleted a few days later, which he was declined. However, he did not even bother to remove the pictures and 
instead began blackmailing her. One of them said that when she brought her laptop for maintenance, the perpetrator copied all of the data from her laptop, as well as the photographs which she had taken on a personal trip, and she was completely unaware of what had happened.

One of the respondents informed that she had misplaced her mobile phone. On her cell phone, she had several personal private photos of her taken with her spouse. When someone contacted her via her Facebook application and began attempting to blackmail her, she became aware of what was going on. The suspect friended her on Facebook, according to another response, and then he pushed her to get married after showing her, his social media status. She was shocked to learn. It had turned out exactly the other way after the wedding.

According to the majority of respondents, they were unfamiliar with the phenomenon under investigation. They were of the view that they became a victim of cyberbullying because of their emotional connectivity with someone via Facebook. They became aware of the term cyberbullying when they shared with someone their trustworthy. Similarly, the majority of the respondents were of the view that after becoming stigmatizing and significantly losing their fame and repute they knew that they had become a victim of cyberbullying.

\section{Experiencing Cyber-Bullying}

Almost all of the respondents were of the view that they had very unpleasant experiences of cyberbullying as they felt suffocation and darkness around them when they came across the incident. The majority of them issued an open cautionary note for others stating that individuals in similar situations should avoid disclosing any information with anybody they do not know and who may subsequently harm them. Following their experiences as victims of cyberbullying, they felt very gloomy. Because of their phobia of being stigmatized, they became much depressed. This situation traumatized them psychologically and they started thinking about destructing themselves even to suicide. At that point, they suggested that all should keep their personal ICT devices like laptops and mobile phones under their custody especially when having secret and sensitive data, and no one should share his/her personal information with anyone whom they do not know or do not think him/her to be trustworthy. Bout three fourth $(75 \%)$ of the respondents advised others not to store their uncovered pictures on their mobile phones, computers, and other information and communication technology (ICT) devices and tools. They also suggested not trust anyone in their life and use their personal devices very carefully. During describing their experiences of cyber-bullying, the female respondents appeared to be feeling sadness, distress, and depression. 


\section{Effects of Cyber-Bullying on Victimized University Graduates}

Cyberbullying has very unpleasant effects on the victimized individuals. Almost all of the respondents affirmed the harmful effects of cyberbullying by saying "We became mentally disturbed and depressed; we were feeling no hunger at all; felt as if no one was ours and wanted to die." Similarly, the majority of the victimized university graduates confined them in one room without talking or interacting with anyone even parents. They thought how they would face others as people around "became very critique on becoming cyber-bullying victimized" instead of being kind and sympathetic to them. One of the female respondents sadly revealed, "My parents arranged my marriage to a person who was considerably twice older than me. Think about me and my life; how miserable I was feeling; and became emotionless at the end. Even so, those who were close to me began to look down upon me as well." One of the female respondents said, "Cyber-bullying developed fear in me, made me helpless and pushed me towards what I never wanted to do during my normal life" as the bully was so deliberately deceptive that he altered her photographs and placed the nude body of another female with her neck. And then he started sending messages to her on her Facebook Messenger with all of such photos. On viewing the photographs, she became horrified. He began blackmailing her and asked her to come to his apartment alone. He warned if she did not agree, he will share all such pictures with her family and all her friends. This incident "Made my life too dark to live."

Another female cyber-bullying victimized graduate said, "I ran after unrealistic and dreamy life and became a victim of cyber-bullying. My life was ruined, darkness prevailed all around me and I was sobbing and lamenting alone." Being fond of luxury life, she was deceived through social media. She decided to get married to the bully (that person) against the will of her parents. However, all the promises of life -the luxury vehicle, the spacious house, and the high status shown on social media appeared just a deception; and her life was ruined.

\section{Immediate Feelings after Cyber-Bullying Victimization}

Usually, the cyber-bullying victimized graduates feel sadness, fear and frustration in their lives immediately after the incident. In response to the question that what was their immediate feelings after victimization; almost all of the respondents affirmed that they were frightened, frustrated, and fearful. One respondent said, "I was thinking to suicide immediately after I was blackmailed." Another respondent affirmed it and said, "The first thing that came to my mind 
was to leave my study and go home; but later on, due to the encouragement of my friends and family I completed my studies and saved my future."

Similarly, the majority of the respondents reported being shocked on becoming cyber-bullied, victimized, and decided to close all their social media accounts. "In this way, they would be safe, and no one would be able to victimize them," they thought. It is generally observed that most of the social IDs are fake and not real. It was confirmed by a majority of the respondents by asserting, "Since they became victimized of cyber-bullying, they became emotionally disturbed and couldn't find a way in life. All of the relationships developed on Facebook and other social media sites are 99\% fake”; and people use such IDs for negative purposes.

\section{Mental and Psychological Well-Being}

Mental and physical health plays an important role in the life of an individual as mentally and physically healthy people seem to be more productive with enhanced workplace performance. In response to a question, the majority of the respondents believed that their mental and psychological conditions improved gradually as a result of their involvement in daily life activities at home and university. Three of them said, "We believe the time is the cure to all grievances as we are living a normal life in all respect." However, some of the respondents were feeling embarrassed when they remind the incident as they said, "We become terrified whenever we think about the incident that happened to us." Another respondent shared his experience that generally he is doing well but becomes aggressive or unhappy when reminds of the incident, according to him, "I feel unpleasant and constantly become aggressive as and when remind of the incident."

\section{Coping with Difficult Circumstances Constructively}

Apparently, coping with difficult circumstances constructively appears a challenging task for cyber-bullying victimized graduates. It demands a lot of passion, patience and hopes to live along with the accepting and consoling attitude of the family and friends. In response to a question of whether the respondents coped with difficult situations; the majority of them was affirmative. They were of the view that if someone intends to do anything, s/he can do. According to her, she had to get rid of her feelings of being victimized very quickly. She tried to change her thinking, re-energized herself for the future and she recovered. Her family helped her a lot and comforted her. She said, "My family not only accepted me but also treated me in a way as if nothing has happened. It helped me in my rehabilitation and brought my life to 
me." Generally, the students use social media and other mobile devices blindly during their life at the university campus and they become prey to cyber-bullying.

One of the respondents said told that she became the victim of cyberbullying during her last semester at the university. In the beginning, she became nervous and a little bit confused feeling in herself. She started thinking to get rid of such feelings and soon she decided not to give up, and she stood up with strength and courage. She shared the whole experience with a trustworthy fellow and released her emotional pain through this catharsis. Meanwhile, her session ended, and the situation was over. She started living afresh with new hopes and new aspirations for her future. Similarly, another respondent affirmed it by saying, "I was courageous when I became cyber-bullying victimized. But I was out of my wits on realizing what people would say and think about me when they know it." Social stigma and negative connotations are often associated with being victimized and put him/her in a miserable life. Almost all of the female cyber-bullying victimized graduates acknowledged it and said, "It is very tough for a woman to bear and live such scenario. Life is on the edge of being destroyed. We have no option except to make a compromise with our misery and stigma for the life."

\section{Factors Contributing towards the Hope for Life}

Cyber-bullying victimization appears to be a painful psychological condition that creates different states [of mind] among the victims. These states may appear in mental disorders or physically harmful conditions or social neglect or segregation. However, some factors and strategies can bring such victims back to their normal lives. Amongst others, acceptance, consoling and encouraging attitudes of family and friends and those who are around for most of the time can play a significant role. It brings among the victims the hope to live.

It was affirmed by a majority of the respondents that their family and friends helped them live their lives. Their inspiration, positive attitude, encouragement, and assistance developed hope for life among them and they returned to their normal life. One of the female respondents said, "After the incident of my victimization, my mother used to come to me every night and she gently talked with me till late at night. In this way, she comforted me. My parents extremely supported me and motivated me to stay strong. They advised me to work as a teacher in a school to stay busy and spend some time with children to freshen my thoughts. It developed confidence in me and helped me in returning to my normal life. I am thankful to my parents." 
Similarly, another respondent acknowledged the facilitation of her father by saying, "My father always negotiated with me and convinced me to pursue a career in education as a teacher. These words of my father inspired me, and I returned to my normal life. He always used to say, "My daughter! Forget what has happened. Think as if nothing has happened. There is no one on the earth without any suffering. Compile yourself, get courage and stand up. Future is yours." One-fourth of the respondents were mothers, and they were of the view that they did get hope for life because of their children. They thought about the future of their children. They said that their younger children particularly, daughters gave them courage and hope to live.

\section{Facing Stumbling Blocks on the Way to Hope for Life}

It appears to be exceedingly difficult for cyber-bullying victims to come to their normal life. It takes time along with a compassionate attitude of the family members, friends, and colleagues. There are different hurdles or some unseen emotional problems, fears of stigma and alike which generally make their life difficult rather normal. Therefore, counselling, and coping strategies play a significant constructive role in recovering the cyber-bullying victimized graduates.

In response to a question that what obstacles they faced in recovering from trauma caused by cyber-bullying victimization; a majority of the respondents affirmed that encountered many challenges; particularly, the negative attitude of the people around, negative connotations, and sometimes segregation. According to them they forgot and ignored all such things with patience and eventually recovered. "Sometimes people publically embarrassed us by calling us with victimized stigma. We felt insulted and humiliated. When we were fed up with a negative attitude of people, we started weeping in isolation and mostly on prayer mats during or after the prayers. It reinforced and encouraged us from within and we recovered" they said.

One of the respondents affirmed that after the incident she was feeling ashamed and thinking either to die or to live in misery. She said, "There were two options for me -the death or the life. I was much confused in deciding what to do. At last, I chose the second option -the life and I recovered." Another respondent said, "There was a battle inside me on either I die or live. It wretched and distorted me emotionally and I was facing a boggling situation in me. During this dilemmatic situation, I thought why I am thinking to die, why not live. It gave me courage from within and a hope to live. Although arriving at this point was uncertain and very much difficult but I am back to my life, or my life is back to me." 
Another respondent asserted that she was very much confused soon after the incident but she had courage and shared with friends and started to aware her fellows about how cyber-bullying. Cyberbullying is a burning issue even for married females. Such a respondent stated that she informed her husband about the whole incident. At first, he became angry, but when she explained that it was not her fault, but her mobile phone was misplaced, he seemed to be normal. After discussion he understood the situation and realised that it was not on her part; eventually, he helped her in recovering. Another respondent said, "I quietly compromised with what happened and what people say for the sake of a normal life." Ignoring what people say encourages the victims to live a normal life.

\section{Towards the Recovery Path}

Rehabilitation of the victimized graduates is necessary to bring them towards their normal life. The majority of respondents were of the view that they recovered through their intentional efforts -sometimes ignoring, sometimes tolerating, sometimes compromising, and sometimes weeping in isolation and catharsis. The majority of the respondents were of the view that they came to their rehabilitation by ignoring and forgetting the incident. They said, "We tried to forget the incident and compromised with what people were saying about us. We tolerated and now are living with new hope." One of the respondents said, "My mother helped me come out of the trauma." Another respondent shared her experience of rehabilitation by saying, "I decided to surrender to my fate. I did not have a choice since I had already left my parents' home for [love] marriage. I had to make a sacrifice in order to save my life."

\section{Avoiding becoming Cyber-Bullied}

Generally, cyber-bullying occurs due to the use of social media and mobile phones. Apparently, one can avoid becoming cyber-bullying victimized by the careful use of social media and information and communication technologies. In response to such a question, the majority of the respondents suggested that parents should keep an eye on their children all the time. They should provide friendly and supportive to their children. They should keep a careful check on their youngsters particularly, their social media, cell phones and laptops. Girls should be given more attention by their mothers. The majority of the respondents said, "Attitude of parents should be as friendly as their children could easily share everything with them confidently." Furthermore, "Never share personal information via social networking sites with anybody you do not know. Do not hand over your ICT devices for repair. Never share your private photos 
with anyone even your trustworthy." In this regard, one of the respondents said, "The whole universe seems to be a fabrication to me."

\section{DISCUSSION AND CONCLUSION}

This study focused on cyber-bullying victimisation, as well as the hope of the victimized graduates to live. For the research purpose, university victimised graduates were interviewed by using the snowball sampling technique. The results of the study are alarming in terms of their nature and intensity -the victimized graduates were blackmailed and thinking of suicide, they were socially stigmatized, they sacrificed their lives and some surrendered or compromised with what the bully said to do, they isolated themselves and alike.

The study also demonstrated that the cyberbullying victimized university graduates excessively used social networking sites (Facebook, Twitter, Snapchat, WhatsApp, and Skype) with a naive faith in everyone which plunged them into cyber-bullying victimization. The respondents of the study appeared to be less or not aware of the term cyber-bullying before they become victimized. The study demonstrated that smartphone, laptop, or social media accounts made university graduates victimized by cyber-bullying. The experience of cyber-bullying appeared as a horrible condition to them as they felt gloomy and developed a fear of social stigma for the rest of life. This study reported the feelings of fear, anger, sadness, ideation, inferiority, and mental distress, which are in accordance with the findings of the study of Balakrishnan (2018) which reported alike results. Cyberbullying has very unpleasant effects on the victimized individuals. The victimized graduates became mentally disturbed and depressed; they were feeling no hunger at all; felt as if no one was theirs' and they even wanted to suicide and die. Different factors contributed towards rehabilitation or recovery of cyber-bullying victimized graduates from the traumatic condition. These results appear to be in line with the results of some other studies including those conducted by Okumu, Kim, Sanders, Makubuya, Small, and Hong (2020); Camp (2016); Reid, Holt, Bowman, Espelage and Green (2016); Zalaquett \& Chatters (2014); Donegan (2012); Schenk \& Fremouw (2012); Goebert, Else, Matsu, ChungDo \& Chang (2011) who affirmed such conditions of the cyber-bullying victimized. It was very difficult for the cyber-bullying victimized graduates to come to their normal life. It took time along with a compassionate attitude of the family members, friends, and colleagues. They encountered many challenges; particularly, the negative attitude of the people around them, negative connotations, and sometimes segregation and isolation. However, counselling, and coping strategies played a significant constructive role in the recovery of cyberbullying 
victimized graduates. Some other studies like Koranteng, Wiafe, and Kuada (2019); Camp (2016); Nixon (2014); Faucher, Jackson \& Cassidy (2014); Slonje, Smith, and Frisén (2013); also reported similar results.

The study suggested that students should avoid sharing their personal information via social networking sites with those people who are not known to them. This study also suggested that parents should have an eye on the social media accounts as well as technology devices and gadgets of their children. Also, educational intuitions should organize awareness seminars to make students aware of cyber-bullying and how to escape from being victimized.

\section{Acknowledgement:}

Cyberbullying victimization is a stigmatizing and sensitive phenomenon in Pakistan. The authors are thankful to the respondents for their participation in the study. They also acknowledge the cooperation of family members of the respondents.

\section{Author(s) Contribution:}

Author 1 contributed to write the literature review, identified study respondents, collected data and contributed in initial draft of the paper. Whereas, Author 2 conceived the idea of the study, contributed in preparation of research tool, envisioned research methodology and finalized the paper. 


\section{REFERENCES}

Abaido, G. M. (2020). Cyberbullying on social media platforms among university students in the United Arab Emirates. International Journal of Adolescence and Youth, 25(1), 407420.

Balakrishnan, V. (2018). Actions, emotional reactions, and cyberbullying-From the lens of bullies, victims, bully-victims, and bystanders among Malaysian young adults. Telematics and Informatics, 35(5), 1190-1200.

Bork-Hüffer, T., Mahlknecht, B., \& Kaufmann, K. (2021). (Cyber) Bullying in schools-when bullying stretches across cON/FFlating spaces. Children's Geographies, 19(2), 241-253.

Busetto, L., Wick, W. \& Gumbinger, C. (2020). How to use and assess qualitative research methods. Neurological Research and Practice, 2(14). https://doi.org/10.1186/s42466020-00059-z.

Camp, N. H. (2016). Restoring trust: A grounded theory study of cyberbullying among young women (Doctoral dissertation, Loyola University Chicago).

Campbell, M., Spears, B., Slee, P., Butler, D., \& Kift, S. (2012). Victims' perceptions of traditional and cyberbullying, and the psychosocial correlates of their victimisation. Emotional and Behavioural Difficulties, 17(3-4), 389-401.

Capital FM (2017). Bullying top concern for parents. Capital FM (August 14). http://www.capitalfm.com/scotland/radio/news/local/bullying-top-concern-forparents/.

Carnoy, M. (2004). ICT in education: Possibilities and challenges. Inaugural Lecture of the UOC, 2005.

Castile, H. (2013). Cyberbullying: An exploration of secondary school administrators' experiences with cyberbullying incidents in Louisiana. Lamar University-Beaumont.

Cohen-Almagor, R. (2017). Social responsibility on the Internet: Addressing the challenge of cyberbullying. Aggression and violent behavior, 39, 42-52.

Cohen-Almagor, R. (2020). Cyberbullying, Moral Responsibility, and Social Networking: Lessons from the Megan Meier Tragedy. European Journal of Analytic Philosophy, 16(1), 75-98.

Craig, W., Boniel-Nissim, M., King, N., Walsh, S. D., Boer, M., Donnelly, P. D., ... \& Pickett, W. (2020). Social media use and cyber-bullying: a cross-national analysis of young people in 42 countries. Journal of Adolescent Health, 66(6), S100-S108. 
Crosslin, K., \& Golman, M. (2014). "Maybe you don't want to face it"-College students' perspectives on cyberbullying. Computers in Human Behavior, 41, 14-20.

Cuervo, A. A. V., Martínez, E. A. C., Quintana, J. T., \& Amezaga, T. R. W. (2014). Differences in types and technological means by which Mexican high school students perform cyberbullying: its relationship with traditional bullying. Journal of Educational and Developmental Psychology, 4(1), 105.

Dehue, F., Bolman, C., \& Völlink, T. (2008). Cyberbullying: Youngsters' experiences and parental perception. CyberPsychology \& Behavior, 11(2), 217-223.

Donegan, R. (2012). Bullying and cyberbullying: history, statistics, law, prevention, and analysis. The Elon Journal of Undergraduate Research in Communications, 3(1), 3342.

Dutta, P., De, C., \& Chandan, A. (2017). Impact of social media on student life: A blessing or curse. International Journal of Multidisciplinary Research and Development Online, 4(7), 479-486.

Espelage, D. L., \& Holt, M. K. (2001). Bullying and victimization during early adolescence: Peer influences and psychosocial correlates. Journal of Emotional Abuse, 2(2-3), 123142.

Faucher, C., Jackson, M., \& Cassidy, W. (2014). Cyberbullying among university students: Gendered experiences, impacts, and perspectives. Education Research International, 2014.

Goebert, D., Else, I., Matsu, C., Chung-Do, J., \& Chang, J. Y. (2011). The impact of cyberbullying on substance use and mental health in a multiethnic sample. Maternal and child health journal, 15(8), 1282-1286.

Griffiths, M., \& Wood, R. T. (2000). Risk factors in adolescence: The case of gambling, videogame playing, and the Internet. Journal of gambling studies, 16(2), 199-225.

Hazlyna, N. (2021). Awareness about Cyberbullying on social media among Female Students in a Malaysian Public University. Turkish Journal of Computer and Mathematics Education (TURCOMAT), 12(3), 1592-1601.

Hinduja, S., \& Patchin, J. W. (2010). Bullying, cyberbullying, and suicide. Archives of suicide research, 14(3), 206-221.

Hussain, I. (2012). A study to evaluate the social media trends among university students. Procedia-Social and Behavioral Sciences, 64, 639-645. 
Kelly, E. V., Newton, N. C., Stapinski, L. A., Slade, T., Barrett, E. L., Conrod, P. J., \& Teesson, M. (2015). Suicidality, internalizing problems and externalizing problems among adolescent bullies, victims, and bully-victims. Preventive medicine, 73, 100-105.

Kiger, M. E. \& Varpio, L. (2020). Thematic analysis of qualitative data: AMEE Guide No. 131, Medical Teacher, DOI: 10.1080/0142159X.2020.1755030

Koranteng, F. N., Wiafe, I., \& Kuada, E. (2019). An empirical study of the relationship between social networking sites and students' engagement in higher education. Journal of Educational Computing Research, 57(5), 1131-1159.

Kowalski, R.M., Limber, S.P., 2013. Psychological, physical, and academic correlates of cyberbullying and traditional bullying. J. Adolesc. Health 53, S13-S20.

Li, Q., Wang, Z., \& Pustaka, A. (2015). Mobile technology and cyberbullying. In Encyclopaedia of mobile phone behavior (pp. 705-718). IGI Global.

Lindsay, B. R. (2011). Social media and disasters: Current uses, future options, and policy considerations.

Nelson, C. A. (2011a). Neural developmental and lifelong plasticity. In R. M. Lerner, F. Jacobs, \& D. Wertlieb (Eds.). Handbook of applied developmental science. Thousand Oaks, CA: Sage.

Nixon, C. L. (2014). Current perspectives: the impact of cyberbullying on adolescent health. Adolescent health, medicine, and therapeutics, 5, 143.

Okumu, M., Kim, Y. K., Sanders, J. E., Makubuya, T., Small, E., \& Hong, J. S. (2020). Gender-Specific Pathways between Face-to-Face and Cyberbullying Victimization, Depressive Symptoms, and Academic Performance among US Adolescents. Child Indicators Research, 13, 2205-2223.

Patchin, J. W., \& Hinduja, S. (2006). Bullies move beyond the schoolyard: A preliminary look at cyberbullying. Youth violence and juvenile justice, 4(2), 148-169.

Patchin, J. W., \& Hinduja, S. (2015). Measuring cyberbullying: Implications for research. Aggression and Violent Behavior, 23, 69-74.

Punch, K. F. (2013). Introduction to social research: Quantitative and qualitative approaches. London: Sage.

Reid, G. M., Holt, M. K., Bowman, C. E., Espelage, D. L., \& Green, J. G. (2016). Perceived social support and mental health among first-year college students with histories of bullying victimization. Journal of Child and Family Studies, 25(11), 3331-3341. 
Schenk, A. M., \& Fremouw, W. J. (2012). Prevalence, psychological impact, and coping of cyberbully victims among college students. Journal of school violence, 11(1), 21-37.

Slonje, R., Smith, P. K., \& Frisén, A. (2013). The nature of cyberbullying, and strategies for prevention. Computers in human behavior, 29(1), 26-32.

Speziale, H. S., Streubert, H. J., \& Carpenter, D. R. (2011). Qualitative research in nursing: Advancing the humanistic imperative. Lippincott Williams \& Wilkins.

Sun, A., \& Chen, X. (2016). Online education and its effective practice: A research review. Journal of Information Technology Education, 15

Sundler, A. J., Lindberg, E., Nilsson, C., \& Palmér, L. (2019). Qualitative thematic analysis based on descriptive phenomenology. Nursing Open, 6(3), 733-739.

Tokareva, E. A., Smirnova, Y. V., \& Orchakova, L. G. (2019). Innovation and communication technologies: Analysis of the effectiveness of their use and implementation in higher education. Education and Information Technologies, 24(5), 3219-3234.

Urista, M. A., Dong, Q., \& Day, K. D. (2009). Explaining why young adults use MySpace and Facebook through uses and gratifications theory. Human Communication, 12(2), 215-229

Wilhelms, E., \& Reyna, V. (2013). Fuzzy trace theory and medical decisions by minors: Differences in reasoning between adolescents and adults. The Journal of Medicine and Philosophy, 38, 268-282.

Wright, M. (2018). Cyberbullying victimization through social networking sites and adjustment difficulties: The role of parental mediation. Journal of the Association for Information Systems, 19(2), 1.

Zalaquett, C. P., \& Chatters, S. J. (2014). Cyberbullying in college: Frequency, characteristics, and practical implications. Sage Open, 4(1), 2158244014526721. 